\title{
Depression and postoperative complications: an overview
}

\author{
Mohamed M. Ghoneim ${ }^{\text {* }}$ and Michael W. O'Hara ${ }^{2}$
}

\begin{abstract}
Background: The interaction of depression and anesthesia and surgery may result in significant increases in morbidity and mortality of patients. Major depressive disorder is a frequent complication of surgery, which may lead to further morbidity and mortality.

Literature search: Several electronic data bases, including PubMed, were searched pairing "depression" with surgery, postoperative complications, postoperative cognitive impairment, cognition disorder, intensive care unit, mild cognitive impairment and Alzheimer's disease.

Review of the literature: The suppression of the immune system in depressive disorders may expose the patients to increased rates of postoperative infections and increased mortality from cancer. Depression is commonly associated with cognitive impairment, which may be exacerbated postoperatively. There is evidence that acute postoperative pain causes depression and depression lowers the threshold for pain. Depression is also a strong predictor and correlate of chronic post-surgical pain. Many studies have identified depression as an independent risk factor for development of postoperative delirium, which may be a cause for a long and incomplete recovery after surgery. Depression is also frequent in intensive care unit patients and is associated with a lower health-related quality of life and increased mortality. Depression and anxiety have been widely reported soon after coronary artery bypass surgery and remain evident one year after surgery. They may increase the likelihood for new coronary artery events, further hospitalizations and increased mortality. Morbidly obese patients who undergo bariatric surgery have an increased risk of depression. Postoperative depression may also be associated with less weight loss at one year and longer. The extent of preoperative depression in patients scheduled for lumbar discectomy is a predictor of functional outcome and patient's dissatisfaction, especially after revision surgery. General postoperative mortality is increased.
\end{abstract}

Conclusions: Depression is a frequent cause of morbidity in surgery patients suffering from a wide range of conditions. Depression may be identified through the use of Patient Health Questionnaire-9 or similar instruments. Counseling interventions may be useful in ameliorating depression, but should be subject to clinical trials.

Keywords: Surgery, Depression, Postoperative complications

\section{Background}

Virtually no one escapes having a condition for which effective treatment requires anesthesia and surgery [1]. Around $15 \%$ of patients who undergo surgery are at high risk of complications, leading to $80 \%$ of all perioperative deaths. Those who survive suffer a substantial reduction in functional independence and long-term survival [2]. Therefore, precise evaluation of each

\footnotetext{
* Correspondence: mohamed-ghoneim@uiowa.edu

${ }^{1}$ Department of Anesthesia - 6JCP, University of lowa Hospitals and Clinics, lowa City, IA 52242, USA

Full list of author information is available at the end of the article
}

patient's risk is important to allow informed decision making by the patient prior to surgery and target specific interventions which may improve the outcome.

Major depressive disorder (MDD) or depression is a heterogeneous disease characterized by low mood, loss of interest and pleasure in normally enjoyable activities, loss of energy, difficulties in thinking and decisionmaking, appetite and sleep disturbances, psychomotor disturbances and suicidal ideation [3]. Anxiety is a frequently co-morbid [4]. In high income countries the average lifetime prevalence is approximately $15 \%$ [5]. 
The World Health Organization (WHO) ranks MDD as the fourth leading cause of disability worldwide and projects that by 2030 , it will be the second leading cause [6]. MDD represents a serious and often recurrent disorder. In addition to reduced general functioning and quality of life, depressed patients suffer from increased physical morbidity and mortality $[7,8]$. The aetiology of the disease is not well understood, and the rates of its diagnostic recognition are poor (35-45\%) [9]. Furthermore, only a minority of diagnosed patients are provided with adequate treatment. Ormel, et al. [10] found that in high-income countries severely disabling mental disorders are only half as likely to be treated compared to serious disabling physical disorders.

\section{Literature search}

Literature search was conducted in the following electronic databases: PubMed, CINAHL, Cochrane Library, PsycNet, Scopus, Web of Knowledge and NCBI. The following search terms were used: depression and surgery, depression and postoperative complications, depression and postoperative cognitive impairment, depression and cognition disorder, depression and intensive care unit, depression and mild cognitive impairment, and depression and Alzheimer's disease. The search was started in June, 2012 down to 1982. We updated the search from June 2012 to April 2014 in Pub Med only. Articles in English language were the only ones pursued. Despite a sizable amount of literature that was examined, we did not run across a single comprehensive review of the interactions of depression with surgery as opposed to interactions with single types of surgeries, e.g., cardiac, bariatric, etc.

In this review we discuss the effects of depression on immunity, cognition and acute and chronic postoperative pain. We follow with discussion on the incidence of postoperative delirium and in patients being cared for in intensive care units. Then we discuss the interaction of depression with some specific surgeries. We conclude with recommendations for management of the depressed patient and future research.

\section{Review of the literature}

\section{Immunity, depression and surgery}

The immune system helps to protect the body against disease, toxic agents, stress and injury. Psychological stress in humans induces an inflammatory response through the production of small messenger molecules, pro-inflammatory cytokines such as interleukin 1beta (IL-1 $\beta$ ), interleukin 6 (IL-6) and tumor necrosis factor alpha (TNF $\alpha)$. All of these are released by macrophages, other peripheral immune cells and microglia, as part of the early acute phase reaction to combat insult or threat $[11,12]$. The state of immune depression is characterized by a depression in T-cell function and a shift toward a $\mathrm{T}_{\mathrm{H}} 2 \mathrm{~T}$-cell phenotype [13].

The immune mechanisms involved in the pathophysiological processes include networks between endocrine, autonomic (the hypothalamic-pituitary-adrenal axis) and neurotransmitter systems [14]. Bufalino, et al. [15], reviewed recently the existing literature on the genetic variants within key elements of the inflammatory system and the risk of depression. There was evidence for the involvement of genes related to inflammatory cytokines and enzymes (COX-2 and PLA2) in the aetiology of depression. In addition, single nucleotide polymorphisms (SNPs) in genes related to the serotonin pathway may play a fundamental role in the shared genetic liability to both depressive symptoms and immune activation. Decreased immunity may increase the risk of postoperative infections and cancer growth in patients harboring malignant tumors.

\section{Surgery and postoperative infections}

Tissue injury following surgery results in depressed immunity leading to an increased risk of infectious complications. Postoperative infections are major causes of increased morbidity, mortality and cost [16]. Several studies reported increased rate of postoperative infections in patients suffering from depression, e.g., after coronary artery bypass surgery (CABG) [17], total knee arthroplasty [18], craniotomies [19], insertion of ventricular assist devices [20]. The latter is of particular serious consequences.

\section{Immunity and malignancy}

Immunity also plays an important role in cancer development, growth and progression. In the setting of human cancer, myeloid-derived suppressor cells (MDSCs) increase in the body including the tumor site [21]. MDSCs and tumor cells form a feedback loop that promotes tumor growth and progression [22]. MDSC release factors that inhibit immunity by blocking $\mathrm{T}$-cell and NK-cell (types of lymphocytes) effector functions, attenuate T-cell migration and enhance angiogenesis, ultimately, promoting tumor growth and progression $[23,24]$.

Although some human studies [25] suggest that patients with depression may be at a higher risk for developing cancer, a larger number of studies [26, 27] suggest that it is unlikely that depression is an independent risk factor for cancer. Some studies reported high prevalence of depression in patients with malignancies [28, 29], while others found the rates of major depression to be similar to those of patients in primary care [30]. This does not contradict the fact that depressive symptoms are commonly experienced by most people in response to sad or stressful life events such as their diagnoses 
with cancer and its often aggressive and debilitating treatments.

In addition to depression affecting the quality of life [31], the mortality of the cancer patient is increased [29, 32]. The causes may be biological, e.g., genetic predisposition, decreased immunity and/or psychosocial. Depressed patients are more likely to smoke [33, 34], or to be alcohol dependent [35] and to be non-compliant with treatments. Spiegel, et al. [36], studied the effect of psychosocial treatment on survival of patients with metastatic breast cancer. One group was randomized to receive group psychotherapy and the other served as a control. After 20 months, patients in the study group lived one and a half year more than those in the control group. La Raja, et al. [37], compared patients who had undergone surgery for breast carcinoma followed by psychotherapy and a control group. After 1 year $94 \%$ of the patients were free of malignancy, compared to $80 \%$ in the control group. More studies in this area are needed.

\section{Depression and postoperative cognitive impairment}

Depressive symptoms flag an increased and robust likelihood of cognitive decline and conversely, cognition at baseline is related to the course of depressive symptoms. The cognitive impairment typically consists of episodic memory impairment, poor attention, decrement of visuospatial skills, information processing and executive dysfunction [38, 39]. As a result, depression may have a major adverse effect on every day functioning. Depression is also a strong risk factor for normal subjects progressing to mild cognitive impairment (MCI) [40]. The construct of MCI identifies the intermediate state of cognitive function between the changes seen in aging and those fulfilling the criteria for dementia of Alzheimer's disease (AD) [41]. The occurrence of depressive symptoms also constitute a predictor for patients who are more likely to progress to Alzheimer's dementia [42].

The syndrome, postoperative cognitive impairment (POCD), is a relatively serious complication of anesthesia and major surgery for elderly patients over 60 years of age. An early cognitive decline in the first week post-surgery of about $30-50 \%$ of patients is followed by a persistent decline in $10-20 \%$ at 3 months postoperatively. It leads to problems with learning, memory, attention and concentration which may affect performance of daily activities and may result in early retirement and resignation from work [43]. Factors related to vascular disease are important for both POCD and depression [43, 44].

As depression commonly leads to cognitive impairment, one may expect that depression should be accounted for in all studies of POCD, however, a recent review of the literature [43] shows otherwise. In the absence of a controlled and randomized study design, it is reasonable to recommend the measurement of depression in POCD trials.

\section{Pain and depression}

Pain has been viewed as a multidimensional experience with sensory, motivational and affective components [45]. There is the experience of the sensory component which includes the perception of location, quality and intensity of the noxious stimulus and the emotional dimension which processes the affective salience or unpleasantness of the stimulus. When pain and depression occur together, they result in worsening of both conditions [46].

\section{Acute postoperative pain}

Many patients suffer from moderate to severe postoperative pain despite recent improvements in pain treatment. Severe pain is associated with decreased patient satisfaction, delayed postoperative ambulation, the development of chronic postoperative pain, increased incidence of pulmonary and cardiac complications, and increased morbidity and mortality [47, 48]. Relatively few studies have investigated the relationship between acute postoperative pain and psychological morbidity. Taenzer, et al. [49] found that depression prior to surgery was significantly correlated with postoperative pain measurements and analgesic requirements. De Cosmo, et al. [50] found that patients with preoperative anxiety and depression had higher pain intensities postoperatively and larger consumption of tramadol.

It is possible also that adequate postoperative analgesia may play a part in protection against postoperative depression. Royse, et al. [51] investigated the effects of high thoracic epidural analgesia versus a patient controlled intravenous analgesia for 3 days in patients following coronary artery bypass surgery (CABG). High thoracic epidural analgesia, which provides excellent pain relief to the majority of patients, resulted in a lower risk of depression for 6 months or more following surgery compared to patients who received patient controlled intravenous analgesia which provides a much greater variability for pain relief [52].

\section{Chronic post-operative pain}

Chronic postsurgical pain (CPSP) is a serious clinical problem [53]. It is a common reason for early retirement and unemployment and represents an extensive drain on societies' resources $[54,55]$.

The factors that seem to affect its incidence include the extent of preoperative pain, trauma during surgery and anxiety and depression [56, 57]. Cancer patients seem particularly susceptible [58]. Depression affects 30-100 \% of patients with chronic pain [53]. Hinrichs-Rocker, et al. [59] systematically reviewed 
the psychosocial predictors and correlates for chronic post-surgical pain. Depression was a strong predictor. Adogwa, et al. [60] and Chaichana, et al. [61] came to the same conclusion. Comorbidity of pain and depression provokes worsening of both conditions [62]. Chronic pain is difficult to treat. It is important therefore to identify patients at high risk for its development and optimize their management.

\section{Mechanisms linking pain and depression}

Pain has been shown to cause altered synaptic connectivity at the prefrontal cortex [63] and hippocampus [64], as well as altered dopamine signaling from the ventral tegmental area [65]. These changes have been known to trigger negative symptoms of depression and may form the link between pain and depression [66]. More recently, dysfunction in the serotonergic (5HT) system has been suggested to plan an important role in the pathophysiology of both conditions. Lebe, et al. [67], demonstrated that pain after lumbar disc surgery modulates the association between $5 \mathrm{HT}$ gene polymorphisms and depression [67].

\section{Postoperative delirium and depression}

Postoperative delirium is a clinical syndrome characterized simply by an acute change in mental status with a fluctuating course, a prominent disturbance in attention, and either disordered thinking or altered level of consciousness. It occurs in $15-53 \%$ of surgical patients over the age of 65 years [68] and is associated with significant morbidity and mortality [69]. Although the pathophysiology of the relationship between the two conditions remains to be clarified, many studies have identified depression as an independent risk factor for postoperative delirium [70, 71]. Patients with preoperative depressive symptoms are more likely to develop postoperative delirium of a longer duration [72] and incomplete recovery to independent functioning after surgery [73].

\section{Depression and the intensive care patient}

The introduction of intensive care units to manage patients who are critically ill after surgery led to their increased survival. However, some of the survivors may suffer from cognitive disabilities and other psychiatric disorders. Rincon, et al. [74] found a $13.7 \%$ incidence of depression on the first day of admission to the ICU. Liberzon, et al. [75] demonstrated a $32 \%$ incidence of depression or PTSD in patients who were admitted to the unit after abdominal aortic surgery. Sukantrat, et al. [76] reported $35 \%$ and $47 \%$ incidence of depression at 3 and 9 months respectively after discharge from the unit.

Davydow, et al. [77] conducted a review of depression in general intensive care unit (ICU) survivors. From 14 studies, the median point prevalence of "clinically significant" depressive symptoms was $28 \%$. Early postICU depressive symptoms were a strong risk factor for subsequent depressive symptoms and were associated with lower quality of life. Future studies should investigate the factors linking individual patients, critical illness and post-ICU recovery with depression. Myhren, et al. [78] studied 194 patients after their discharge from ICU. Optimism was a strong predictor for less anxiety and depression symptoms; while pessimism had the opposite effect. Intervention by clinical psychologists when needed during the ICU stay promotes patients' recoveries from depression and other psychiatric complications [79].

Depression is common in patients with diabetes and increases the rate of complications from this disease [80]. Diabetic patients with two or more complications, especially neuropathy or nephropathy are at high risk of depression [81]. This knowledge can help clinicians to identify patients at risk of depression and facilitate early treatment. Patients with diabetes and comorbid depression have a greater risk of ICU admission. Davydow, et al. [82] suggested that improving depression treatment in patients with diabetes could potentially prevent hospitalization for critical illnesses and lower healthcare costs. Depression and anxiety preceding myocardial infarction were associated with increased incidence of cardiac complications in coronary care units and ICUs, following infarction [83]. Identification and treatment of depression may prevent these complications. Cerebral stroke is another cause for admission to ICU. Poststroke depression is a very frequent complication with an estimated prevalence of as high as $80 \%$ and with increased risk of mortality [84].

\section{Influence of depression on surgical mortality}

In addition to increased rate of mortality in surgical patients with depression who were also suffering from heart disease [85, 86], malignancy $[26,87]$ or other specific causes [18], Abrams, et al. [88] investigated surgical patients admitted to ICUs. Anxiety and depression increased the risk of death. Cuijpers, et al. [89] also reported an increased risk of all causes of mortality in a meta-analysis of community studies. Several causes for the increased mortality have been suggested. One is non-compliance of depressed patients with medical recommendations [90, 91]. It has also been suggested that patients with existing psychiatric morbidity may be more likely to undergo surgery by a lower-quality surgeon [92]. Another factor is the tendency of depressed patients to lead a less than healthy lifestyle, e.g. tobacco smoking and excessive alcohol consumption [93]. Depressed patients may seek advice at a later stage of illness, lack effective communications with physicians and the delays 
resulting from treatment of depression before surgery [88].

Depression has a strong association with suicide. The probability of attempted or successful suicide in depressive people is much higher than for the general population $[94,95]$. Bariatric surgery patients in particular have a higher suicide rate than the general population. Tindle, et al. [96] reported a completed suicide rate of 13.7 per 10,000 for male patients and 5.2 per 10,000 for female patients, compared to 2.4 and 0.7 respectively in the general U.S. population. Peterhänsel, et al. [94] reviewed the results of thirty studies concerning bariatric surgery and completed suicide. They estimated a suicide rate of $4.1 / 10,000$ person-years, higher than the general population. As will be reported later when discussing bariatric surgery, obesity has a strong association with depression. Although for many patients their depression symptoms improve following surgery, they remain an issue for some patients.

\section{Depression and some specific surgeries}

Patients who undergo different surgical procedures probably have different pathophysiologies which may affect their postoperative course. We chose three surgeries that have been adequately studied in their relation to depression namely, CABG, bariatric surgery and spine surgery.

\section{Depression and CABG}

For some patients with coronary artery disease, despite successful surgery, the outcome can be disappointing, because of psychological impairments. The prevalence of depression approximates between $30 \%$ and $40 \%$ and it increases the risk of morbidity and mortality. It increases the incidence of postoperative delirium, unplanned hospital admissions and cardiac events, e.g., arrhythmias, return of angina symptoms [97, 98]. Doering, et al. [17, 73] studied patients at discharge from the hospital and 6 weeks later. Depressive symptoms were associated with infections, impaired wound healing, poor emotional and physical recovery, and impaired quality of life.

One consistent feature of the papers reviewed was the recommendation that clinicians ought to routinely assess patients' depressive and anxiety symptoms prior to surgery which also conforms with the recommendation by the American Heart Association [99]. Future randomized and controlled studies are needed to confirm the value of these recommendations.

\section{Bariatric surgery and depression}

Extreme obesity, characterized by a body mass index (BMI) of $40 \mathrm{~kg} / \mathrm{m}^{2}$ or greater, is associated with significantly increased mortality, principally from cardiovascular disease, type 2 diabetes and several cancers [100]. It is also associated with increased risk of depression [101]. Surgically induced weight loss is a valid treatment.

\section{Depression in bariatric surgery candidates}

Methodologic limitations, including the absence of welldefined control groups, the absence of randomization and the use of suboptimal psychometric measures [102], prevent definitive interpretation of the rates of psychopathology observed in bariatric surgery candidates. Questionnaires which assess self-report symptoms may be often biased by confounding covariates as compared to symptoms confirmed by an interview [103]. An epidemiological study of nearly 40,000 individuals found that persons who had a BMI of $40 \mathrm{~kg} / \mathrm{m}^{2}$ or higher were nearly five times more likely to have experienced an episode of major depression in the past year than were individuals of average weight [104]. This and other findings strongly suggest that extremely obese individuals are more vulnerable to depression, although the factors responsible for this susceptibility are not clear. Weight related stigmatization and the emotional distress associated with the medical complications of morbid obesity may be contributors $[105,106]$. Therefore, candidates for bariatric surgery should be assessed for depression and those in need should be treated.

\section{Changes after bariatric surgery}

Most studies reported a significant decrease in depression and anxiety rating scores and improvement in quality of life scores after surgery. And there is usually a positive association between the decrease in the depression and anxiety scores and the amount of weight loss [107]. Deactivation of inflammatory pathways, normalization of HPA axis functioning, and reduction of psychological distress due to weight loss might be the explanation. Postoperative depression was associated with less weight loss at the 24-36 month follow-up assessment [103].

Some patients may regain some of the weight they had lost, usually within 2-4 years. The follow-up data of the Swedish Obese Subjects study [107, 108] showed that the depression scores increased again over time after a strong initial improvement. Importantly, greater weight loss was significantly associated with greater reduction of depressive symptoms in the long term. Close surveillance of patients might help to identify those who would benefit from interactions that target depression as a potential mediator for poorer weight loss outcome. It may also identify patients who harbor suicidal ideation.

\section{Depression and spine surgery}

Lumbar discectomy is the most common surgical procedure for patients experiencing back and leg pain from herniated lumbar discs. However, not all patients will 
benefit; some will be vulnerable to poor clinical outcome [61], especially with revision surgery [60]. Depression and anxiety are common in many disease states of chronic pain, as was mentioned before and are potential predictors of surgical outcomes. Some studies reported high rates of preoperative depression $[109,110]$, and failed back surgery syndrome is a common problem with enormous costs to patients, insurers and society [111]. Its commonest cause is depression [60], which should be assessed and treated preoperatively to avoid another failed operation.

Löbner, et al. [109] in a longitudinal observation study, identified several factors which increase the risk of depression, e.g., females, older age, lower education level, etc. Future studies should include a non-surgery control group of patients together with the surgical cohort in a randomized fashion to build a consensus for screening and management of patients for disc surgery.

A framework for counselling interventions in major surgery patients is detailed in Fig. 1.

\section{Clinical management of depression}

Even in a busy surgical practice, it is relatively easy to screen for depression. There are numerous tools available that can be administered pre-operatively, e.g., the Patient Health Questionnaire-9 [112] which has 9 items that assess the symptoms of major depression, ${ }^{3}$ each of which are rated on a 4-point (0-3) scale. A score of 10 or above indicates that the patient is at high risk for major depression (sensitivity
$=.88$; specificity $=.88)$. For patients who screen positive, the next step is to do a more formal evaluation of the patient's depression and to develop a treatment plan if indicated by a psychiatrist or clinical health psychologist. These types of consultations usually can occur quickly and should not ordinarily delay surgery. One major question will be whether the depression symptoms are largely reflective of the underlying disease for which the surgery is being performed, e.g., hypothyroidism, hyperparathyroidism or whether the symptoms reflect comorbid depression. For the surgeon (and patient) the question is whether to delay surgery until the patient has at least showed a response to the treatment. In cases which cannot be delayed, pharmacotherapy or cognitive behavior therapy can begin as soon as the patient is sufficiently recovered. For purely elective surgeries, the operation may be delayed until the patient has responded to treatment.

Unfortunately, it is not always the case that patients will respond to psychotherapy or medications quickly. Moreover, some patients will come to surgery with a long history of failed treatments for depression and will hold out little likelihood that a new round of depression treatment will be successful. To complicate matters more, perioperative use of serotonin reuptake inhibitors which are used for treatment may contribute to adverse postoperative outcomes which include death [113]. Following surgery it is recommend that patients should be screened for depression, particularly those who were

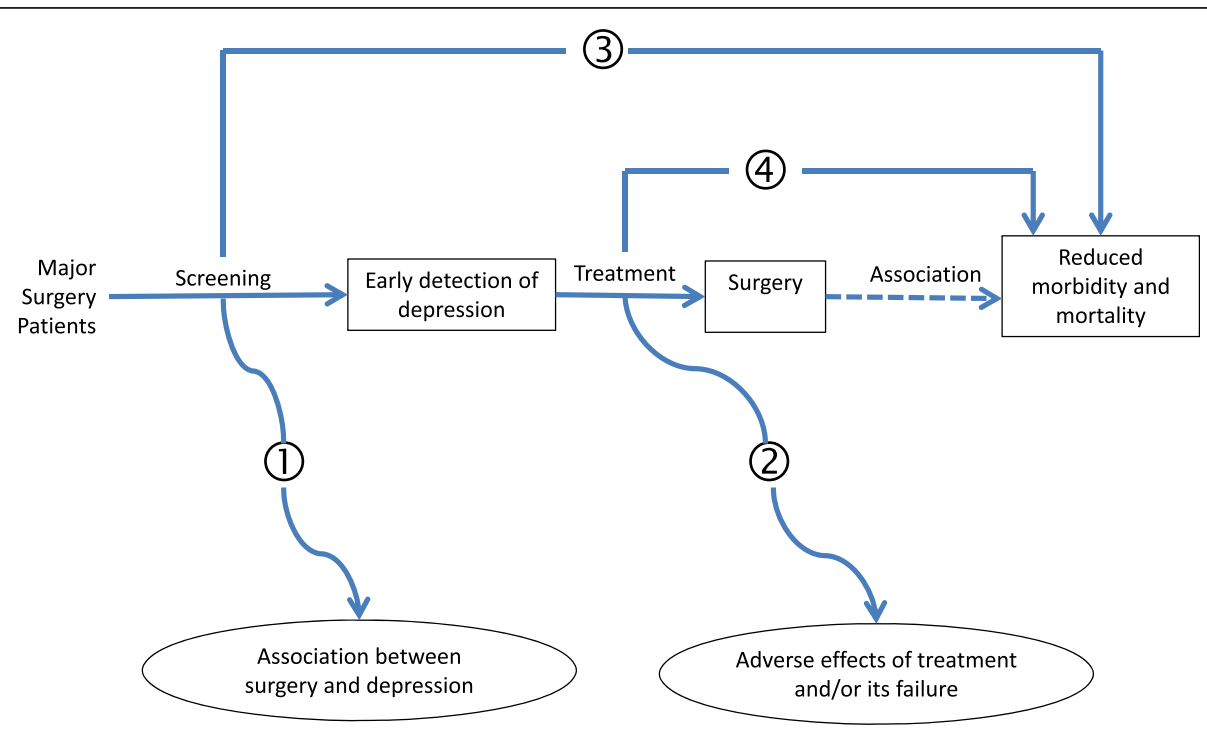

Fig. 1 A framework for counselling interventions in major surgery patients. The numbers refer to answers to key questions as follows: (1) There are not enough studies comparing surgery with non-surgery cohorts. (2) There are potential adverse effects of treatment and/or its failure (3) and (4). There is a need for randomized and controlled trials to prove the efficacy of screening and/or treatment of depression before anesthesia and surgery in reducing postoperative morbidity and mortality. 
identified as depressed before surgery. Again, referrals to consultation liaison psychiatry and clinical psychology can be made in the context of positive screens.

\section{Conclusions}

The available literature suggests that depression is prevalent in patients before major surgery. Nonalleviated, it may predict increased morbidity and mortality after the operation. It may be associated with greater postoperative pain, higher incidence of postoperative infections, progression of malignant tumors, poor health-related quality of life as well as other complications. Accurate prediction of perioperative risk enables informed consent for patients before surgery, guides clinical decision making in the perioperative period and allows clinical audit [114]. Multiple tools are available [115], but unfortunately, none of them include major depression among the patientrelated factors.

The evidence base for the detrimental effects of depression in the surgical patient consists mainly of relatively small studies which make chance findings more likely and prevent considering all possible contributing factors (Fig. 1). They are mostly single center studies and are therefore subject to confounding, particularly when they are non-blinded which is usually the case. It is not sufficient simply to demonstrate that poor clinical outcomes are more frequently associated with depression. Higher rates of psychiatric disorders in surgical than in non-surgical patients would suggest that anesthesia and surgery contribute to the emergence of psychiatric morbidity. Unfortunately, such studies are uncommon. Large multicenter randomized controlled trials are needed to confirm that screening and treatment of depression improve the outcome of surgery (unless randomization is deemed ethically improper). Until such studies have been performed, we must recognize the limitations of our database and make best use of them to reduce the perioperative risk in the patients.

Ultimately the etiology and the molecular nature of the brain deficits in depression need to be elucidated and new approaches to reverse them have to be found.

Table 1 Recommendations for enhancement of the recovery of the depressed surgical Patient

- Adoption of reliable and feasible screening process.

- Use of large multi-center randomized controlled trials to confirm the value of screening and treatment of depression.

- Adoption of a multi-modal approach of peri-operative care.

- Inclusion of major depression in risk stratification tools for predicting morbidity and mortality in adult patients undergoing major surgery.

- More use of clinical registries in studies for the depressed surgical patient.
No new antidepressant has been developed in the last quarter century. In the meantime more work is needed in the public health arena. A multimodal approach to perioperative care, and the use of clinical registries may help to improve the management of the surgical patient [116]. They provide a nationwide, prospective, observational database; therefore avoiding performance bias, which can occur if patients are recruited from selected surgeons and centers (Table 1). In the future, these efforts may change the potentially high-risk depressed surgical patient to a low or no risk one.

\section{Abbreviations}

AD: Alzheimer's disease; BMI: body mass index; CABG: coronary artery bypass surgery; CPSP: chronic postsurgical pain; ICU: intensive care unit; MCl: mild cognitive impairment; MDD: major depressive disorder; MDSC: myeloidderived suppressor cells; POCD: postoperative cognitive impairment; SNP: single nucleotide polymorphism; WHO: World Health Organization.

\section{Competing interests}

There are no competing interests.

\section{Authors' contributions}

MG drafted the majority of the article. MO wrote portions of it and reviewed all of it. Both authors read and approved the final manuscript.

\section{Acknowledgements}

We thank Mr. Brad Lind for his expert management during the writing of this article.

\section{Author details}

${ }^{1}$ Department of Anesthesia - 6JCP, University of lowa Hospitals and Clinics, lowa City, IA 52242, USA. ²Department of Psychological and Brain Sciences, University of lowa, lowa City, IA 52242, USA.

Received: 22 May 2014 Accepted: 21 January 2016

Published online: 02 February 2016

\section{References}

1. Gawande A. Two hundred years of surgery. N Engl J Med. 2012; 366:1716-23.

2. Grocott MPW, Pearse RM. Prognostic studies for perioperative risk: robust methodology is needed. Br J Anaesth. 2010;105:243-5.

3. American Psychiatric Association. Diagnostic and statistical manual of mental disorders. 5th ed. Arlington: American Psychiatric Publishing; 2013.

4. Mineka S, Anand D, Sumner JA. Important issues understanding comorbidity between generalized anxiety disorder and major depressive disorder. In: Richards CS, O'Hara MW, editors. The Oxford Handbook of Depression and Comorbidity. New York: Oxford University Press. (in press)

5. Bromet E, Andrade LH, Hwang I, Sampson NA, Alonso J, de Girolamo G, et al. Cross-national epidemiology of DSM-IV major depressive episode. BMC Med. 2011;9:90.

6. Mathers C, Loncar D. Updated projection of global mortality and burden of disease, 2002-2030: data sources, methods and results. Geneva: WHO; 2005.

7. Guerini F, Morghen S, Lucchi E, Bellelli G, Trabucchi M. Depressive symptoms and one year mortality among elderly patients discharged from a rehabilitation ward after orthopaedic surgery of the lower limbs. Behav Neurol. 2010;23:117-21.

8. Thombs BD, de Jonge P, Coyne JC, Whooley MA, Frasure-Smith N, Mitchell AJ, et al. Depression screening and patient outcomes in cardiovascular care: a systematic review. JAMA. 2008;300:2161-71.

9. Wancata J, Windhaber J, Bach M, Meise U. Recognition of psychiatric disorders in nonpsychiatric hospital wards. J Psychosom Res. 2000; 48:149-55.

10. Ormel J, Petukhova M, Chatterji S, Aquilar-Gaxiola S, Alonso J, Angermeyer $M C$, et al. Disability and treatment of specific mental and physical disorders across the world. Br J Psychiatry. 2008;192:368-75. 
11. Kaster MP, Gadotti VM, Calixto JB, Santos AR, Rodrigues AL. Depressive-like behavior induced by tumor necrosis factor-alpha in mice. Neuropharmacology. 2012;62:419-26.

12. Pollak Y, Yirmiya R. Cytokine-induced changes in mood and behaviour: implications for depression due to general medical condition, immunotherapy and antidepressive treatment. Int J Neuropharmacol. 2002;5:389-99.

13. Elenkov IJ. Systemic stress-induced Th2 shift and its clinical implications. Int Rev Neurobiol. 2002;52:163-86

14. Sperner-Unterweger B, Kohl C, Fuchs D. Immune changes and neurotransmitters: possible interactions in depression? Prog NeuroPsychopharmacol Biol Psychiatry. 2014;48:268-76

15. Bufalino C, Hepgul N, Aguglia E, Pariante CM. The role of immune genes in the association between depression and inflammation: A review of recent clinical studies. Brain Behav Immun. 2012;31:31-47.

16. Marik PE, Flemmer M. The immune response to surgery and trauma: Implications for treatment. J Trauma Acute Care Surg. 2012;73:801-8.

17. Doering LV, Cross R, Vredevoe D, Martinez-Maza O, Cowan MJ. Infection, depression, and immunity in women after coronary artery bypass: A pilot study of cognitive behavioral therapy. Altern Ther Health Med. 2007;13:18-21.

18. Bozic KJ, Lau E, Kurtz S, Ong K, Berry DJ. Patient-related risk factors for postoperative mortality and periprosthetic joint infection in medicare patients undergoing TKA. Clin Orthop Relat Res. 2012;470:130-7.

19. Chang SM, Parney IF, McDermott M, Barker 2nd FG, Schmidt MH, Huang W, et al. Perioperative complications and neurological outcomes of first and second craniotomies among patients enrolled in the Giloma Outcome Project. J Neurosurg. 2003;98:1175-81.

20. Gordon RJ, Weinberg AD, Pagani FD, Slaughter MS, Pappas PS, Naka Y, et al. Prospective, multicenter study of ventricular assist device infections. Circulation. 2013;127:691-702

21. Greten TF, Manns MP, Korangy F. Myeloid derived suppressor cells in human diseases. Int Immunopharmacol. 2011;11:802-7.

22. Filipazzi $P$, Huber $V$, Rivoltini L. Phenotype, function and clinical implications of myeloid-derived suppressor cells in cancer patients. Cancer Immunol Immunother. 2011;61:255-63.

23. Gros A, Turcotte $S$, Wunderlich JR, Ahmadzadeh M, Dudley ME, Rosenberg SA. Myeloid cells obtained from the blood but not from the tumor can suppress T cell proliferation in patients with melanoma. Clin Cancer Res. 2012;18:5215-23.

24. Tang S, Lotze MT. The power of negative thinking: which cells inhibit tumor immunity? Clin Cancer Res. 2012;18:5157-9.

25. Penninx BW, Guralnik JM, Pahor M, Ferrucci L, Cerhan JR, Wallace RB, et al. Chronically depressed mood and cancer risk in older persons. J Natl Cancer Inst. 1998;90:1888-93.

26. Acher J, Hutchinson I, Korszun A. Mood and malignancy: head and neck cancer and depression. J Oral Pathol Med. 2008;37:255-70.

27. Levinson JL, Bemis C, Presberg BA. The role of psychological factors in cancer onset and progression: a critical appraisal. In: Lewis CE, OBrien R, Barraclough J, editors. The Psychoimmunology of Cancer. 2nd ed. New York: Oxford University Press; 2002. p. 246-64.

28. Massie MJ. Prevalence of depression in patients with cancer. J Natl Cancer Inst Monogr. 2004;32:57-71.

29. Stommel M, Given BA, Given CW. Depression and functional status as predictors of death among cancer patients. Cancer. 2002;94:2719-27.

30. Simon AE, Palmer SC, Coyne JC. Cancer and depression. In: Steptoe A, editor. Depression and Physical IIIness. Cambridge: Cambridge University Press; 2006. p. 211-37.

31. Duffy SA, Terell JE, Valenstein M, Ronis DL, Copeland LA, Connors M. Effect of smoking, alcohol, and depression on the quality of life of head and neck cancer patients. Gen Hosp Psychiatry. 2002;24:140-7.

32. Hjerl K, Andersen EW, Keiding N, Mouridsen HT, Mortensen PB, Jørgensen T. Depression as a prognostic factor for breast cancer mortality. Psychosomatics. 2003;44:24-30.

33. Kendler KS, Gardner CO, Prescott CA. Toward a comprehensive developmental model for major depression in women. Am J Psychiatry. 2002:159:1133-45.

34. Haukkala A, Uutela A, Vartiainen E, McAlister A, Knekt P. Depression and smoking cessation: the role of motivation and self-efficacy. Addict Behav. 2000;25:311-6.

35. Grant BF, Stinson FS, Dawson DA, Chou SP, Dufour MC, Compton W, et al. Prevalence and co-occurrence of substance use disorders and the independent mood and anxiety disorders: results from the National Epidemiologic Survey on Alcohol and Related Conditions. Arch Gen Psychiatry. 2004;61:807-16.

36. Spiegel D, Bloom JR, Kraemer HC, Gottheil E. Effect of psychosocial treatment on survival of patients with metastatic breast cancer. Lancet. 1989;1:888-91.

37. La Raja MC, Virno F, Mechella M, D'Andrea M, D'Alessio A, Ranieri E, et al. Depression secondary to tumors in patinets who underwent surgery for mammary carcinoma: psycho-pharmaceutical and psychotherapeutic care. J Exp Clin Cancer Res. 1997;16:209-16.

38. Thomas AJ, O'Brien JT. Depression and cognition in older adults. Curr Opin Psychiatry. 2008;21:8-13.

39. Vasudev A, Saxby BK, O'Brien JT, Colloby SJ, Firbank MJ, Brooker H, et al. Relationship between cognition, magnetic resonance white matter hyperintensities and cardiovascular autonomic changes in late-life depression. Am J Geriatr Psychiatry. 2012;20:691.9.

40. Steenland K, Karnes C, Seals R, Carnevale C, Hermida A, Levey A. Late-life depression is a risk factor for mild cognitive impairment or Alzheimer's disease in 30 US Alzheimer's disease centers. J Alzheimers Dis. 2012; 31:265-75.

41. Petersen RC. Mild cognitive impairment. N Engl J Med. 2011:364:2227-34.

42. Gabryelewicz T, Styczynska M, Luczywek E, Barczak A, Pfeffer A, Androsiuk $W$, et al. The rate of conversion of mild cognitive impairment to dementia: predictive role of depression. Int J Geriatr Psychiatry. 2007;22:563-7.

43. Ghoneim MM, Block Rl. Clinical, methodological and theoretical issues in the assessment of cognition after anaesthesia and surgery: a review. Eur J Anaesthesiol. 2012;29:409-22.

44. Gorelick PB, Scuteri A, Black SE, Decarli C, Greenberg SM, ladecola C, et al. Vascular contributions to cognitive impairment and dementia. A statement for healthcare professional from the American Heart Association/American Stroke Association. Stroke. 2011;42:2672-713.

45. Melzack R. Psychological aspects of pain. Implications for neural blockade. In: Cousins MJ, Bridenbaugh PO, editors. Neural Blockade in Clinical Anesthesia and Management of Pain. Philadelphia: Lippincott-Raven; 1998

46. Gureje O. Treating chronic pain in the context of comorbid depression. Pain. 2008;134:3-4

47. Gerbershagen HJ, Aduckathil S, van Wijck AJ, Peelen LM, Kalkman CJ, Meissner W. Pain intensity on the first day after surgery: a prospective cohort study comparing 179 surgical procedures. Anesthesiology. 2013;118:934-44.

48. Joshi GP, Kehlet H. Procedure-specific pain management. The road to improve postsurgical pain management? (editorial). Anesthesiology. 2013; 118:780-2.

49. Taenzer P, Melzack R, Jeans ME. Influence of psychological factors on postoperative pain, mood and analgesic requirements. Pain. 1986;24:331-42.

50. De Cosmo G, Congedo E, Lai C, Primieri P, Dottarelli A, Aceto P. Preoperative psychologic and demographic predictors of pain perception and tramadol consumption using intravenous patient-controlled analgesia. Clin J Pain. 2008;24:399-405.

51. Royse C, Remedios C, Royse A. High thoracic epidural analgesia reduces the risk of long-term depression in patients undergoing coronary artery bypass surgery. Ann Thorac Cardiovasc Surg. 2007:13:32-5.

52. Royse C, Soeding P, Blake D, Pang J. Prospective randomized trial of high thoracic epidural analgesia for coronary artery bypass surgery. Ann Thorac Surg. 2003;75:93-100.

53. Cohen SP, Raja SN. Prevention of chronic postsurgical pain. The ongoing search for the holy grail of Anesthesiology (Editorial). Anesthesiology. 2013; 118:241-3.

54. Christensen FB. Lumbar spinal fusion. Outcome in relation to surgical methods, choice of implant and postoperative rehabilitation. Acta Orthopaedica Scandinavica. 2004;75:31-41.

55. Walid MS, Zaytseva N. The relationship of unemployment and depression with history of spine surgery. Perm J. 2011;15:19-22.

56. Katz J, Seltzer Z. Transition from acute to chronic postsurgical pain; risk factors and protective factors. Expert Rev Neurother. 2009:9:723-44.

57. Kehlet $\mathrm{H}$, Jensen TS, Woolf $\mathrm{CJ}$. Persistent postsurgical pain: risk factors and prevention. Lancet. 2006:367:1618-25.

58. Porter LS, Keefe FJ. Psychosocial issues in cancer pain. Cur Pain Headache Rep. 2011;15:263-70.

59. Hinrichs-Rocker A, Schultz K, Järvinen I, Lefering R, Simanski C, Neugebauer EA. Psychosocial predictors and correlates for chronic post-surgical pain (CPSP) - a systematic review. Eur J Pain. 2009;13:719-30. 
60. Adogwa O, Parker SL, Shau DN, Mendenhall SK, Aaronson OS, Cheng JS, et al. Preoperative Zung depression scale predicts outcome after revision lumbar surgery for adjacent segment disease, recurrent stenosis, and pseudoarthrosis. Spine J. 2012;12:179-85.

61. Chaichana KL, Mukherjee D, Adogwa O, Cheng JS, McGirt MJ. Correlation of preoperative depression and somatic perception scales with postoperative disability and quality of life after lumbar discectomy. J Neurosurg Spine. 2011;14:261-7

62. Price DD. Psychological and neural mechanisms of the affective dimension of pain. Science. 2000;288:1769-72.

63. Geha PY, Baliki MN, Harden RN, Bauer WR, Parrish TB, Vania Apkarian A. The brain in chronic CRPS pain: abnormal gray-white matter interactions in emotional and autonomic regions. Neuron. 2008;60:570-81.

64. Kodama D, Ono H, Tanabe M. Altered hippocampal long-term potentiation after peripheral nerve injury in mice. Eur J Pharmacol. 2007;574:127-32.

65. Wood PB. Mesolimbic dopaminergic mechanisms and pain control. Pain 2006;120:230-4.

66. Nestler EJ, Hyman SE. Animal models of neuropsychiatric disorders. Nat Neurosci. 2010:13:1161-9.

67. Lebe M, Hasenbring MI, Schmieder K, Jetsche K, Harders A, Epplen JT, et al. Association of serotonin-1A and -2A receptor promoter polymorphisms with depressive symptoms, functional recovery, and pain in patients 6 months after lumbar disc surgery. Pain. 2013;154:377-84.

68. Inouye SK. Delirium in older persons. N Engl J Med. 2006;354:1157-65.

69. Witlox J, Eurelings LS, de Jonghe JF, Kalisvaart KJ, Eikelenboom P, van Gool WA. Delirium in elderly patients and the risk of postdischarge mortality, institutionalization, and dementia: a meta-analysis. JAMA. 2010;304:433-51.

70. Rudolph $J$, Marcantonio ER. Postoperative delirium: Acute change with long-term implications. Anesth Analg. 2011;112:1202-11.

71. Kazmierski J, Kowman M, Banach M, Fendler W, Okonski P, Banys A, et al. Incidence and predictors of delirium after cardiac surgery: results from the IPDACS Study. J Psychosom Res. 2010;69:179-85.

72. Leung JM. Postoperative delirium: are there modifiable risk factors? Eur J Anaesthiol. 2010;27:403-5.

73. Doering LV, Moser DK, Lemankiewicz W, Luper C, Khan S. Depression, healing, and recovery from coronary artery bypass surgery. Am J Crit Care. 2005;14:316-24

74. Rincon HG, Granados M, Unutzer J, Gomez M, Duran R, Badiel M, et al. Prevalence, detection and treatment of anxiety, depression, and delirium in the adult critical care unit. Psychosomatics. 2001;42:391-6.

75. Liberzon I, Abelson JL, Amdur RL, King AP, Cardneau JD, Henke P, et al. Increased psychiatric morbidity after abdominal aortic surgery: risk factors for stress-related disorders. J Vasc Surg. 2006;43:929-34

76. Sukantarat K, Greer S, Brett S, Williamson R. Physical and psychological sequelae of critical illness. Br J Health Psychology. 2007;12:65-74.

77. Davydow DS, Gifford JM, Desai SV, Bienvenu OJ, Needham DM. Depression in general intensive care unit survivors: a systematic review. Intensive Care Med. 2009;35:796-809.

78. Myhren H, Ekeberg O, TØien K, Karlsson S, Stokland O. Posttraumatic stress, anxiety and depression symptoms in patients during the first year postintensive care unit discharge. Crit Care. 2010;14:R14.

79. Peris A, Bonizzoli M, lozzelli D, Migliaccio ML, Zagli G, Bacchereti A, et al. Early intra-intensive care unit psychological intervention promotes recovery from post traumatic stress disorders, anxiety and depression symptoms in critically ill patients. Crit Care. 2011;15:R41.

80. de Groot M, Anderson R, Freedland KE, Clouse RE, Lustman PJ. Association of depression and diabetes complications: A meta-analysis. Psychosom Med. 2001;63:619-30

81. van Steenbergen-Wijenburg KM, van Puffelen AL, Horn EK, Nuyen J, van Dam PS, van Benthem TB, et al. More co-morbid depression in patients with Type 2 diabetes with multiple complications. An observational study at a specialized outpatient clinic. Diabet Med. 2011;28:86-9.

82. Davydow DS, Russo JE, Ludman E, Ciechanowski P, Lin EHB, Von Korff M, et al. The association of comorbid depression with intensive care unit admission in patients with diabetes: A prospective cohort study. Psychosomatics. 2011;52:117-26.

83. Huffman JC, Smith FA, Blais MA, Taylor AM, Januzzi JL, Fricchione GL. Preexisting major depression predicts in-hospital cardiac complications after acute myocardial infarction. Psychosomatics. 2008;49:309-16.

84. Bartoli F, Lillia N, Lax A, Crocamo C, Mantero V, Carrà G, et al. Depression after stroke and risk of mortality: A systematic review and meta-analysis. Stroke Res Treat. 2013;2013:862978.
85. Ariyo AA, Haan M, Tangen CM, Rutledge JC, Cushman M, Dobs A, et al. Depressive symptoms and risks of coronary heart disease and mortality in elderly Americans. Circulation. 2000;102:1773-9.

86. Penninx BW, Beekman AT, Honig A, Deeg DJ, Schoevers RA, van Eijk JT, et al. Depression and cardiac mortality: Results from a community-based longitudinal study. Arch Gen Psychiatry. 2001;58:221-7.

87. Goodwin JS, Zhang DD, Ostir GV. Effect of depression on diagnosis, treatment, and survival of older women with breast cancer. J Am Geriatr Soc. 2004:52:106-11.

88. Abrams TE, Vaughan-Sarrazin M, Rosenthal GE. Influence of psychiatric comorbidity on surgical mortality. Arch Surg. 2010;145:947-53.

89. Cuijpers P, Smit F. Excess mortality in depression: a meta-analysis of community studies. J Affect Disord. 2002;72:227-36.

90. Ziegelstein RC, Fauerbach JA, Stevens SS, Romanelli J, Richter DP, Bush DE. Patients with depression are less likely to follow recommendation to reduce cardiac risk during recovery from a myocardial infarction. Arch Intern Med. 2000;160:1818-23.

91. Reikmann N, Kronish IM, Haas D, Gerin W, Chaplin WF, Burg MM, et al. Persistent depressive symptoms lower aspirin adherence after acute coronary syndromes. Am Heart J. 2006;152:922-7.

92. Li Y, Glance LG, Cai X, Mukamel DB. Are patients with coexisting mental disorders more likely to receive CABG surgery from low-quality cardiac surgeons? The experience in New York state. Med Care. 2007:45:587-93.

93. van Gool CH, Kempern GI, Bosma H, van Boxtel MPJ, Jolles J, van Eijk JTM. Associations between lifestyle and depressed mood: longitudinal results from the Maastricht Aging Study. Am J Public Health. 2007;97:887-94.

94. Peterhänsel C, Petroff D, Klinitzke G, Kersting A, Wagner B. Risk of completed suicide after bariatric surgery: a systematic review. Obes Rev. 2013;14:369-82.

95. Harris EC, Barraclough B. Suicide is an outcome for mental disorders - a meta-analysis. Br J Psychiatry. 1997;170:205-28.

96. Tindle HA, Omalu B, Courcoulas A, Marcus M, Hammers J, Kuller LH. Risk of suicide after long-term follow-up from bariatric surgery. Am J Med. 2010; 123:1036-42.

97. Tully PJ, Baker RA. Depression, anxiety, and cardiac morbidity outcomes after coronary artery bypass surgery: a contemporary and practical review. J Geriatr Cardiol. 2012;9:197-208.

98. Tully PJ, Baker RA, Knight JL. Anxiety and depression as risk factors for mortality after coronary bypass surgery. J Psychosom Res. 2008;64:285-90.

99. Lichtmen JH, Bigger Jr JT, Blumenthal JA, Frasure-Smith N, Kaufmann PG, Lespérance F, et al. Depression and coronary heart disease. Recommendations for screening, referral, and treatment: a science advisory from the American Heart Association prevention committee of the council on cardiovascular nursing, council on clinical cardiology, council on epidemiology and prevention, and interdisciplinary council on quality of care and outcomes research: endorsed by the American Psychiatric Association. Circulation. 2008:118:1768-75.

100. Rosenbaum M, Leibel RL, Hirsch J. Obesity. N Engl J Med. 1997;337:396-407.

101. Wadden TA, Phelan S. Assessment of the quality of life in obese individuals. Obes Res. 2002;105:50-7.

102. Wadden TA, Sarwer DB, Fabricatore AN, Jones L, Stack R, Williams NS Psychosocial and behavioral status of patients undergoing bariatric surgery: what to expect before and after surgery. Med Clin N Am. 2007;91:451-69

103. de Zwaan M, Enderie J, Wagner S, Mühlhans B, Ditzen B, Gefeller O, et al. Anxiety and depression in bariatric surgery patients: a prospective follow-up study using structured clinical interviews. J Affect Disord. 2011;133:61-8.

104. Onyike CU, Crum RM, Lee HB, Lyketsos CG, Eaton WW. Is obesity associated with major depression? Results from the Third National Health and Nutrition Examination Survey. Am J Epidemiol. 2003;158:1139-47.

105. Puhl R, Brownwell KD. Bias, discrimination, and obesity. Obes Res. 2001;9: 788-805.

106. Fabricatore AN, Wadden TA, Sarwer DB, Faith MS. Health-related quality of life and symptoms of depression in extremely obese persons seeking bariatric surgery. Obes Surg. 2005;15:304-9.

107. Karlsson J, Sjostrom L, Sullivan M. Swedish obese subjects (SOS): an intervention study of obesity: two-year follow-up of health-related quality of life (HRQL) and eating behavior after gastric surgery for severe obesity. Int J Obes. 1998;22:113-26.

108. Sullivan M, Karlsson J, Sjostrom L, Taft C. Why quality of life measures should be used in the treatment of patients with obesity. In: Bjorntrop P, 
editor. International textbook of obesity. London: John Wiley and Sons; 2001. p. 485-510.

109. Löbner M, Luppa M, Matschinger H, Konnopka A, Meisel HJ, Günther L, et al. The course of depression and anxiety in patients undergoing disc surgery: a longitudinal observational study. J Psychosom Res. 2012;72:185-94.

110. Sinikallio $\mathrm{S}$, Aalto T, Airaksinen $\mathrm{O}$, Lehto SM, Kröger H, Vinamäki $\mathrm{H}$. Depression is associated with poorer outcome of lumbar spinal stenosis surgery: a two-year prospective follow-up study. Spine. 2011;36:677-82.

111. Guyer RD, Patterson M, Ohnmeiss DD. Failed back surgery syndrome: Diagnostic evaluation. J Am Acad Orthop Surg. 2006;14:535-43.

112. Kroenke K, Spitzer RL, Williams JBW. The PHQ-9: Validity of a brief depression severity measure. J Gen Internal Med. 2001;16:606-13.

113. Auerbach AD, Vittinghoff E, Maselli J, Pekow PS, Young JQ, Lindenauer PK. Perioperative use of selective serotonin reuptake inhibitors and risks for adverse outcomes of surgery. JAMA Intern Med. 2013;173:1075-81.

114. Pearse RM, Holt PJE, Grocott MPW. Managing perioperative risk in patients undergoing elective non-cardiac surgery. BMJ. 2011;343:d5759.

115. Moonesinghe SR, Mythen MG, Das P, Rowan KM, Grocott MP. Risk stratification tools for predicting morbidity and mortality in adult patients undergoing major surgery: qualitative systematic review. Anesthesiology. 2013;119:959-81.

116. Jain SH, Conway PH, Berwick DM. A public-private strategy to advance the use of clinical registries. Anesthesiology. 2012;117:227-9.

\section{Submit your next manuscript to BioMed Central} and we will help you at every step:

- We accept pre-submission inquiries

- Our selector tool helps you to find the most relevant journal

- We provide round the clock customer support

- Convenient online submission

- Thorough peer review

- Inclusion in PubMed and all major indexing services

- Maximum visibility for your research

Submit your manuscript at www.biomedcentral.com/submit

) Biomed Central 